\title{
Ecological Studies on the Alaskan Arctic Slope
}

\author{
FRANK A. PITELKA ${ }^{1}$
}

In the following paragraphs tundra, or terrestrial studies will be emphasized; and in considering tundra the emphasis will be placed on animal studies. But the influence of NARL in expanding ecological knowledge of the Arctic is of course manifest in all realms of the environment, on both physical and biological sides. Ecology in the Alaskan Arctic has moved forward in the last two decades mainly through the leadership of some five agencies: the University of Alaska, the Arctic Health Research Laboratory of the U.S. Public Health Service, the U.S. Geological Survey, the Atomic Energy Commission, and the Naval Arctic Research Laboratory. Among these, the impact on the field of arctic ecology by NARL has certainly been the strongest to date. I do not underestimate the significant roles of the other agencies, least of all that of the University, whose expanding programs of today signal impressively the yet larger role it will play in the arctic tomorrow. But at this time, the prime position of NARL in ecology of the American Arctic is clear. Beginning in 1947, there has been a continuing flow of investigators from various universities, colleges, and government agencies converging onto NARL with the result that the Alaskan Arctic Slope and adjacent waters of the Arctic Basin now comprise one of the best-known sectors of the Arctic, and in many respects the best known.

The impact of NARL in ecology of course extends internationally. This is well exemplified for us by the recent publication of Eric Hultén's Flora of Alaska with its circumpolar distributional maps. One can only wish that our ties with colleagues in the USSR were not so thin and elusive, so frail and feeble. They have the bear's share of the circumpolar zone of tundra. There is so much about it we should like to know, so much the Russians could tell us and show us, as we want to show and tell them. But speaking only for animal ecology of the tundra, the role of the Russians in this field is nowhere near proportional to their share of the arctic land mass. Being of Slavic origin myself, I may be permitted a bit of Slavic bluntness: The Russian output in ecology of arctic animals does not exploit the ideas in the field as they are at present developing in the West. Most papers we have seen are surprisingly unquantitative and without disciplined problem focus. Their titles are ambitious, but methods are often inadequately described and data are incompletely or scantily presented. A general review by B. A. Tikhomirov (1959) on animal-vegetation interactions, translated into English in 1966 for international consumption, is heavily descriptive in its content and preoccupied with the elementary fact that plants and animals interact; but it is admirable in its wide sweep of the topic and in the degree to which it raises

\footnotetext{
1Department of Zoology and Museum of Vertebrate Zoology, University of California, Berkeley, California, U.S.A.
} 
questions and urges teamwork in concentrated study on particular areas. The impressive output of papers in ecology by the Russians' own neighbours - the Poles, the Czechs, and the Finns - provides many models of the sort of information we should like to see from the Eurasian tundra.

There is a new side to the international impact which NARL can have in its support of arctic ecology. I refer to the International Biological Program. This program is dedicated to the study of biological productivity and human welfare. The IBP research programs of the United States are several, but for only two is study in the arctic a specially important consideration. These are the programs on analysis of ecosystems and on human adaptability. Substantial progress has already been made in the study of arctic tundra as an ecosystem, thanks to NARL and to organizations which sponsor research there. This is also true for studies of Eskimos, and indeed an IBP-sponsored study of Wainwright village is already launched. But extent of U.S. commitment to IBP moneywise is, at this writing, still uncertain, and a considerable expansion of research effort in basic ecology of tundra could occur. In this the University of Alaska and scientists depending on NARL would be prime movers. Anyone interested in details of these prospects can refer to my report on an IBP meeting for tundra held at College in October 1968 (Pitelka 1969).

We may first ask ourselves, why should biologists come, or continue to come, to the Arctic to do research? The prime incentives all come from the special features of arctic environment and the special biological conditions which these generate: the low temperatures, the short growing season (or conversely the long winter season), the relatively low numbers of plant and animal species, the distinctive, low-statured vegetation mat, the distinctive make-up of the animal life, and the simple organization of the tundra communities that they comprise. The various questions biologists ask about a particular kind of plant or animal or about a particular kind of tundra habitat all arise from one or more of these environmental features. These questions may be mechanistic, having to do with functional efficiency and adaptation, or they may be descriptive and historical, having to do with distribution and evolution. Who among biologists are attracted to the Arctic? Not just ecologists, but physiologists and behaviorists, less frequently other types of biologists. Working with the biologists are the climatologists, geomorphologists, soil scientists and others who also provide essential knowledge about conditions of existence in the Arctic.

A descriptive base for arctic ecology has of course been provided by explorers and naturalists over the past 200 years. The scientific command of this knowledge grew relatively rapidly, for several reasons: first, the attractiveness of the Arctic, in its remoteness and hostility, to explorers and naturalists; second, the low species diversity; and third, the similarity of the biota through the almost continuous zone of arctic land mass. Fourth, the three factors just mentioned rather soon promoted comparative studies of arctic biotas, which in turn reinforced concern for new information. The result is that our knowledge about distribution of plants and animals of the north is now impressively detailed. But whereas this detail is relatively rich on a large scale, it is usually poor on a small, or tighter local scale, and we have much to learn. 
For the ecologists' goal is not merely knowledge of the general conditions of existence, but more particularly, the goal is knowledge of the consequences of co-existence among plants and animals. In other words, given the conditions of existence characteristic of the Arctic, we want to know how the plants and animals co-existing in a tundra habitat are functionally interrelated and integrated, what regulatory mechanisms prevail in their populations, and what strategies of exploitation are common or even peculiar to tundra. Co-existing groups of plants and animals in their physical setting of tundra, or further south, display common features of functional organization and are called ecosystems. But in tundra, prevailing responses of plant and animal populations to the extreme environmental conditions mentioned above, make the tundra particularly suited for comparative and analytic work about how ecosystems are organized and how they function. Indeed, tundra is a low-temperature extreme among ecosystem-types on the land areas of the earth and hence it assumes a special importance to the theory of ecosystems; hence, also, the concern about faunistic and floristic work on a tighter, local scale.

I will put this last point more strongly. Future faunistic and floristic work of a general sort, as an end in itself, is less and less justifiable in the Arctic; it should rather be done in conjunction with the special needs of ecologists and physiologists whose more focused interests and more problem-oriented approaches raise fundamental questions which often call for the critical help of taxonomists. An excellent example is provided by work under way near Barrow. Here knowledge about decomposition processes is woefully scant (and this is true also for all other ecosystems). On tundra, flies or insects of the order Diptera are especially rich in species and comprise a dominant part of the total insect life. Their larvae are an important but as yet unstudied component in the utilization and breakdown of dead organic matter. Moreover, for some groups of animals, such as sandpipers, they are a primary class of food. Our ignorance of the life cycles of common fly species and their population fluctuations thwart analyses of how these sandpipers depend on a highly varying and rather unpredictable food base (Holmes and Pitelka 1968). Hence the need for detailed studies of the taxonomy and biology of flies of the Barrow area. We need this knowledge of the fly fauna on a local scale broadly for effective analysis of tundra as an ecosystem and particularly for analysis of the conditions that generate the peculiar styles of living we observe among animals in that ecosystem. The excellent Finnish work on chironomids a key group of flies highly important in tundra economics - exemplifies the sort of intensive study which should be undertaken in the American Arctic (see, for example, Lindeberg 1968, and Syrjämäki 1967, and their earlier papers cited therein).

From these comments on a class of decomposers and a class of predators, we can turn to some aspects of research on tundra as a total system. First, some general points to indicate the magnitude of the job. In Fig. 1 we have a scheme showing the essential components of a life system, be it that of the earth's biosphere or that of just one particular ecosystem. Components and the rates at which energy and nutrients are transferred between them differ between ecosystem-types both qualitatively and quantitatively, and so one thinks of this scheme in realistic 


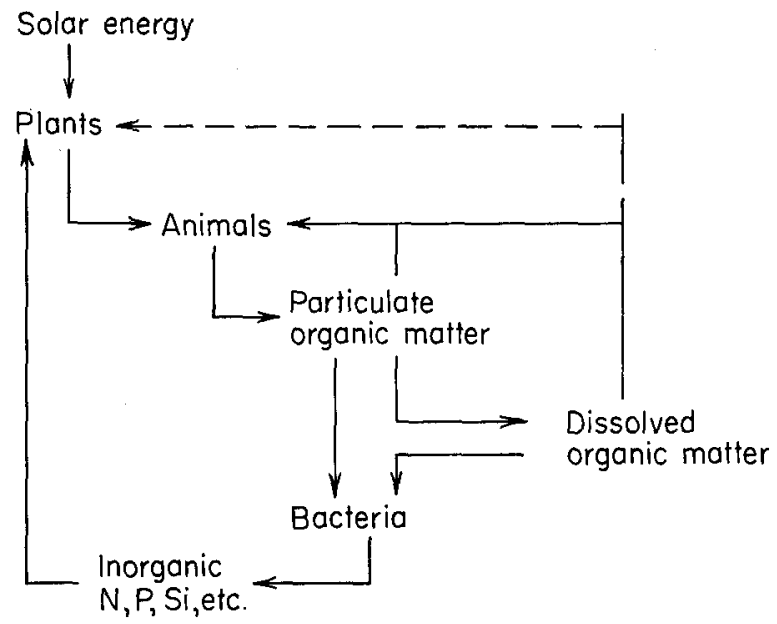

FIG. 1. Energy cycle in the biosphere (from Dunbar, 1968).

terms only for a given ecosystem, a given block of land or water, or a set of such blocks. Furthermore, the scheme shown in Fig. 1 is simplified to barest essentials comprising any ecosystem. A more useful, even if somewhat overwhelming scheme is shown in Fig. 2, where components or compartments (the boxes) and transfer paths (the numbered arrows) give us a more precise breakdown for functional analyses. This is the scheme adopted by the IBP through international conferences for tundra which have taken place in England and Norway. It is planned that studies of tundra in America, Greenland, England, Norway, Sweden, Finland and (hopefully) the USSR will be coordinated so that compatible data will result and so that, minimally, compatible data will be available for certain key components and transfers shown by the heavy-walled boxes and heavy arrows. Clearly, we want and need to know how and to what degree a system such as tundra, which is regionally distinguished by its structural features and its species membership, is also distinctive in its functional properties. The basic pattern of functional organization of ecosystems is the same everywhere, but ecosystems differ significantly, for example, in the proportion of plant matter taken up by herbivores, versus plant matter which dies and is converted by decomposers, versus plant

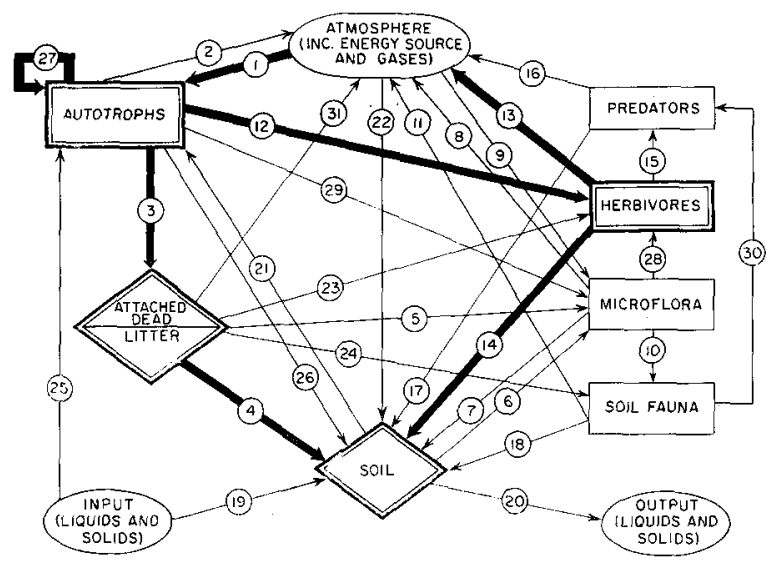

FIG. 2. Flow diagram for energy and nutrients in tundra ecosystems. 
matter held in storage as undecomposed organic matter such as peat. The comparison of several tundra sites will provide a test of the generality for tundra of results obtained at any one of them. At the same time, parallel studies in other kinds of ecosystems such as grassland and conifer forest will provide a base for the comparisons we need to discover and assess the special functional properties of tundra.

An entrée into the topic ecosystems as this thinking applies to the Arctic can be obtained from a recent book by Dunbar (1968). He helps to bring out that the last 30 years' research in community and ecosystem ecology have sharpened our grasp of the analytical framework necessary to a proper understanding of productional processes in natural habitats. It has become clear, and IBP has hastened this realization, that for most major advances in the field, organized teamwork of ecologists with physiologists, geomorphologists, soil scientists, climatologists and others is essential. The job before us is enormous, as Fig. 2 shows, but with effective collaboration among researchers and with the use of computers and data-storage procedures, modelling operations and systems analysis, the job should become tractable. A program such as this has already been launched for American grassland with an operational base at Fort Collins, Colorado.

A new urgency for knowledge of tundra as an ecosystem results from sudden developments triggered by the oil discovery in northern Alaska. We know how delicate and unaccommodating tundra is in the face of the gung-ho, hit-and-run style of white man on the economic make; and we know from many small-scale examples how easily and quickly tundra is disturbed and defaced by man. Now we have a Texas-size threat to a land doubtfully able to take it. One recent newspaper headline asked very plainly, "Will Alaska's Oil Start 'Rape of Arctic'?" Our need to deal with ecology of normal tundra has therefore become crucial for now, even more than earlier, we must also deal with ecology of damaged tundra. As Robert Weeden (1969) recently observed, "Neither science nor government was - or is - prepared for the discovery of oil in the Arctic." This puts the fact of our job to us starkly and bluntly.

Tundra is fascinating to ecologists everywhere for yet another reason: this is the occurrence of strong fluctuations in populations of animals, and particularly the occurrence of cycles in a few plant-eating mammals and birds. For this topic lemmings are legendary, even though a 3 to 4 -year cycle occurs among relatives of the lemming at lower latitudes also, down to San Francisco and Jerusalem at least. But this cyclicity is by far most dramatic in the Arctic, and while interest in the mechanism of the cycle continues everywhere, it is especially intense there. It is a fact that for the Arctic, the most concentrated work on the subject has been undertaken near Barrow, thanks again to NARL. The lemming cycle has been monitored since 1949 . The fifth cyclic population peak since then is expected to occur this coming summer (1969). The monitoring done by a number of workers has produced a basic picture of cycle characteristics which now provides a basis for a new phase of research. [For background information on the lemming cycle see: Pitelka (1957); Krebs (1964), and Mullen (1968).] Particularly timely would be intensive work on the metabolic physiology and feeding ecology of lemmings related to the cyclic phase. 
Ecology of the vegetation base which supports this cycle also needs continuing study. That plant production of grass-sedge tundra in the Barrow area is temperature limited (as has been stated for tundra elsewhere) was shown by A. M. Schultz (unpublished manuscript) in experiments at NARL in which blocks of vegetation and sod brought into a greenhouse and maintained at $20-25^{\circ} \mathrm{C}$. produced 3 to 4 times as much dry biomass as similar vegetation growing under field temperatures. But natural vegetation experimentally fertilized in the field produced 4 times as much dry biomass as that left unfertilized, and its nitrogen and phosphorus content per unit weight was twice that of controls so that there was an 8 -fold increase in yield of $\mathbf{N}$ and $\mathbf{P}$ on the treated plot. Thus, astride the temperature effect is a more fundamental limitation, that of nutrient supply. Here we need a great deal more quantitative observation and measurement along with experimentation, not just in relation to lemmings but in relation to all parts of the food web depending on the plant base.

I want lastly to bring out a general point about the tactics some arctic animals use in coping with the marginal existence offered by tundra - tactics whose understanding adds to ecosystem theory. Let me say parenthetically that I do not subscribe to the notion that evolution of species richness in the Arctic is still catching up because of the recency of glacier recession. I do not think that evolution is proceeding any more rapidly in the Arctic than elsewhere. Capacity of animals to disperse is strong in spite of their differing equipments. The relative success of population pressures by animals of all kinds through time to use tundra resources is shown by the fact that the fauna of, for example, flies exceeds 100 species for a given arctic area whereas the number of species of beetles may be just 5 or 6 .

For highly mobile animals such as birds, there is a wide range of tactics, or strategies, in life-style among arctic species, even among those co-existing on the same acreage of tundra. By "life-style" I refer to what more technically is

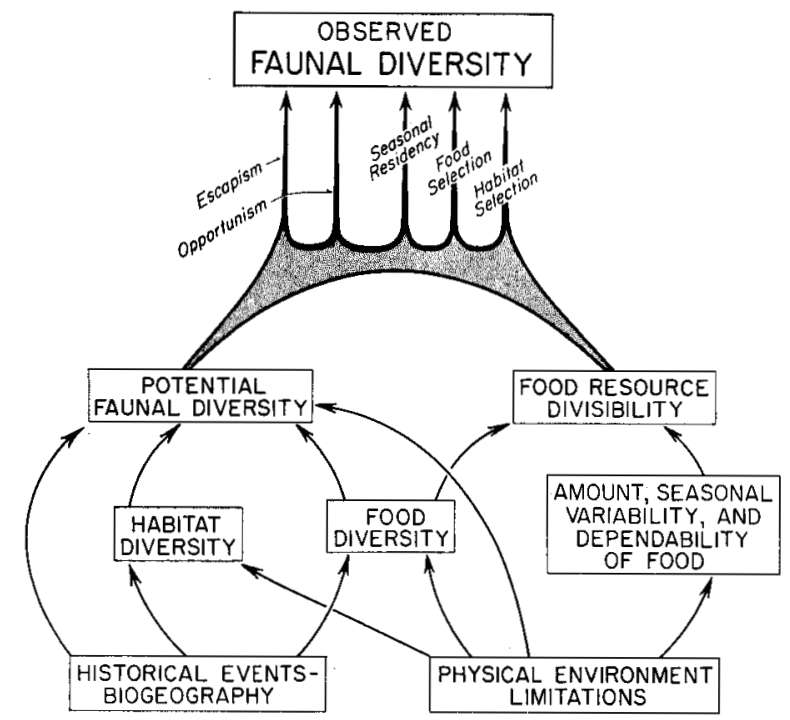

FIG. 3. Factors (boxes) and strategies (arrows) influencing observed faunal diversity within an ecosystem-type such as tundra. 
often termed "social system"; that is, the adaptive pattern of deployment of the individuals of a population through time and space, especially with regard to production and survival of young. Variety in social systems among co-existing species is an evolutionary tactic serving to "push" the capacity of a habitat to support more species. Tundra and its bird life provide an excellent example.

Fig. 3 illustrates a base of thinking about richness or diversity of species in a given ecosystem (we are concerned about diversity of animal species, hence "faunal" diversity). The foundations of this matter packaged in the lower part of the figure are, for the most part, general knowledge of modern ecology and biogeography. Our concern now is with the arrows representing resultants for tundra from the mesh of factors determining species diversity anywhere. First, as elsewhere, species of birds separate into different habitats, and within each habitat, they separate according to type of food used. In tundra, seasonal change is strong, and the species diversity is greatly augmented by migrants coming North to breed. But among these, the commitment to breeding does not include necessarily a regular cost, so to speak, paid by tundra resources. Migrants do not all stay $2 \frac{1}{2}$ to 3 months, nor are they on a given acreage of tundra every year. Some species practice "opportunism," breeding in numbers beside more conservative, regularly present kinds of birds when food is abundant. These are "prosperity" opportunists. There can also be "depression" opportunists, exploiting some foods too scarce for specialists but sufficient if combined. An especially significant strategy is "escapism" (MacLean and Pitelka unpublished manuscript). Various species, notably among ducks and sandpipers, come to the Arctic to get the breeding effort going, but then one parent departs quickly, followed by the other as soon as possible, so that the growth of young is risked minimally by the energy needs of parents. Various aspects of this topic are developed in more detail in manuscripts being prepared for publication elsewhere. The timing and spacing features of the bird populations are the better known parts of this picture; the food relationships are the difficult, more speculative parts. The fact of a variety of tactics remains, and this variety is evidently so wide among tundra birds because of the highly fluctuating character of the environment and, therefore, the highly variable food supply.

It is because of the occurrence of these distinctive strategies at times even among closely related species such as sandpipers (Holmes and Pitelka 1968) that the tundra is a significant source of insight into how species diversity can build up and thus how the membership of an ecosystem can build up. While this aspect of ecology stresses knowledge of particular groups or organisms such as birds, their population dynamics, physiology, and behaviour, it is absolutely basic, as I think we can see, to the furtherance of the theory of ecosystem structure and function.

Here, then, are several aspects of ecology which are central in the field as a whole and whose study in the Arctic is especially promising and even critical. None of this can occur without facilities and support of the sort NARL has provided. In its new home, it will be yet more effective in the growth of ecology and of arctic science generally. 


\section{ACKNOWLEDGEMENTS}

I should like to acknowledge my heavy professional and personal indebtedness to the Naval Arctic Research Laboratory and to all persons and agencies that have made and continue to make NARL possible.

My work at Barrow began in 1951, after a brief but warm invitation to apply for support sent to me in October 1950, by Ira L. Wiggins, who was then beginning a term as the scientific director of NARL. Ira Wiggins' kind gesture was the trigger for a long series of new research associations and friendships with fellow scientists and students, here and abroad. The Arctic has been our common bond, and the tundra, in reality or in theory, has been a target we have shared in continuing inquiry. For all this, my humble thanks and boundless gratitude to NARL.

\section{REFERENCES}

DUNBar, M. J. 1968. Ecological development in polar regions. Englewood Cliffs, N.J.: Prentice-Hall, 119 pp.

HOLMES, R. T. and F. A. PITELKA. 1968. Food overlap among coexisting sandpipers on northern Alaskan tundra. Systematic Zoology, 17: 305-18.

HULTÉN, ERIC. 1968. Flora of Alaska and neighboring territories. Stanford: Stanford University Press, $1008 \mathrm{pp}$.

KREBS, CHARLES J. 1964. The lemming cycle at Baker Lake, Northwest Territories, during 1959-62. Montreal: Arctic Institute of North America Technical Paper, 15. 104 pp.

LINDEBERG, B. 1968. Population differences in Tanytarsus gracilentus (Holmgr.) (Dipt., Chironomidae). Annales Zoologici Fennici, 5: 88-91.

MULLEN, D. A. 1958. Reproduction in brown lemmings (Lemmus trimucronatus) and its relevance to their cycle of abundance. University of California Publications in Zoology, $85.24 \mathrm{pp}$.

PITElKA, F. A. 1957 (re-issued 1967). Some characteristics of microtine cycles in the Arctic. In: H. P. Hansen, ed. Arctic Biology. Corvallis: Oregon State University Press, pp. 153-84.

1969. Report on a U.S. - IBP meeting for tundra, held at the University of Alaska 9-11 October 1968. 44 pp., photoprinted. (Obtainable from the author or the U.S. National Committee for IBP, National Academy of Sciences, Washington, D.C. 20418).

SYRJÄMÄKI, J. 1967. Laboratory studies on the swarming behaviour of Chironomus strenzkei Fittkau in litt. (Dipt. Chironomidae). Annales Zoologici Fennici, 4: 19-28.

TIKномIROV, в. А. 1959. The interrelationships of the animal life and vegetational cover of the tundra. Akademiia Nauk SSSR, Botanicheskii Institut imeni V. L. Komarova. (Israel Program for Scientific Translations, cat. no. 1301: IV, 68 pp., 1966.)

WEEDEN, R. B. 1969. Arctic oil: its impact on wilderness and wildlife. In: Proceedings of the 11th Biennial Wilderness Conference, San Francisco: Sierra Club. (in press). 